\title{
WRKY33 MODULATES THE RESPONSES TO LOW NITROGEN SUPPLY OF CONTRASTING N-USE EFFICIENT EGGPLANTS
}

\author{
Antonio Mauceri ${ }^{1}$, MARIA ROSA ABENAVOLI ${ }^{1}$, Laura Toppino ${ }^{2}$, Sayantan Panda ${ }^{3}$, \\ Francesco Mercati ${ }^{4}$, Meriem Aci ${ }^{1}$, Asaph Aharoni ${ }^{3}$, FRANCESCO SUNSERI ${ }^{1}$, Giuseppe \\ Rotino $^{2}$, and Antonio Lupini ${ }^{1}$ \\ ${ }^{1}$ Università degli Studi Mediterranea di Reggio Calabria \\ ${ }^{2}$ Consiglio per la ricerca in agricoltura e l'analisi dell'economia agraria \\ ${ }^{3}$ Weizmann Institute of Science \\ ${ }^{4}$ National Research Council
}

July 3, 2020

\begin{abstract}
Nitrogen use efficiency (NUE) is an important and complex crops trait and its improvement represents a strategy to maintain high yield reducing $\mathrm{N}$-supply. We report the genome-wide transcriptomic analysis of four eggplants contrasting for NUE to identify key genes related to the NUE pathway, after short- and long-term low-N exposure, in both root and shoot. Coexpression Gene Networks (CGN) analysis permitted to identify up-regulated differential expressed genes (DEGs) involved in the light reaction pathway, the biological processes response to inorganic substance, abiotic stimulus and cellular response to nitrogen starvation in high NUE genotypes. Some transcription factor (TF) were up-regulated in the N-use efficient genotypes, in particular, WRKY33 showed a significant up-regulation triggering the higher expression of 21 genes cluster including other TFs, many of which associated to N-metabolism. To validate our results, an independent de novo experiment including two other NUE-contrasting genotypes, at both low and high N supply, was carried out. Interestingly, the high significant WRKY33 expression and its cluster were confirmed in the high NUE genotypes at low-N supply. Moreover, the WRKY33 role was confirmed in Arabidopsis as the 35S::AtWRKY33 over expressing line showed a more competitive root system able to uptake more efficiently $\mathrm{N}$ from the soil.
\end{abstract}

\section{Hosted file}

Manuscript.docx.doc available at https://authorea.com/users/339576/articles/465738-wrky33modulates-the-responses-to-low-nitrogen-supply-of-contrasting-n-use-efficient-eggplants 

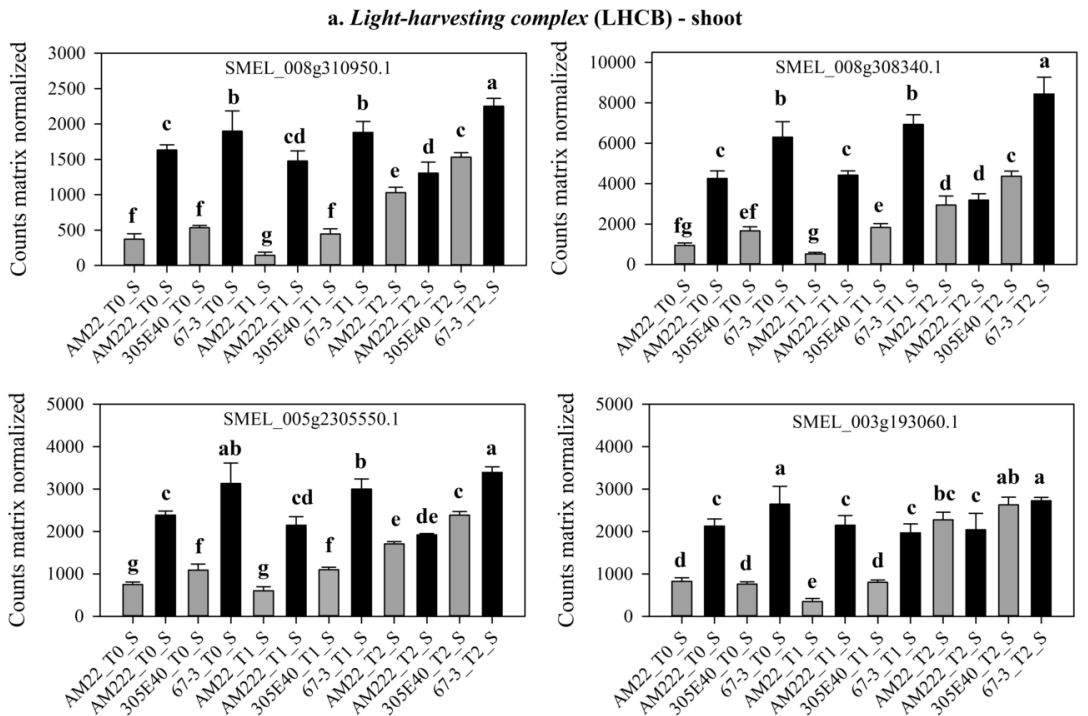

b. Ferrodoxin-NADP reductase (FNR) - shoot
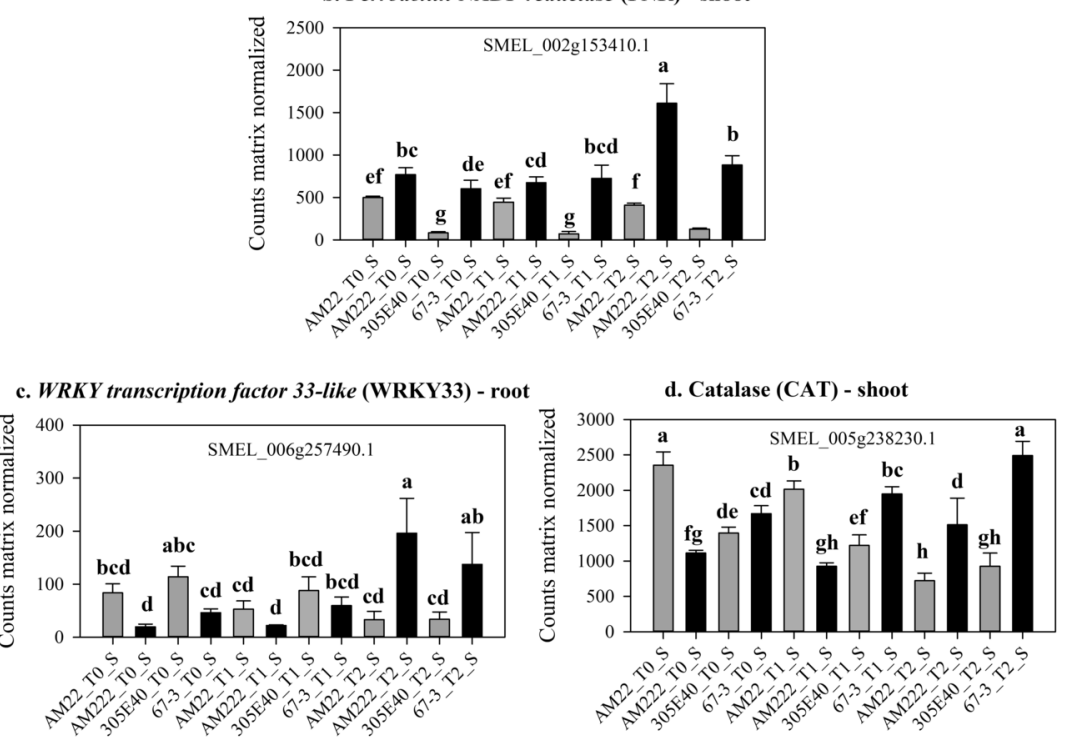


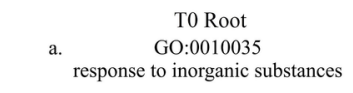

AM222 vs. AM22 $305 E 40$ vs. AM22

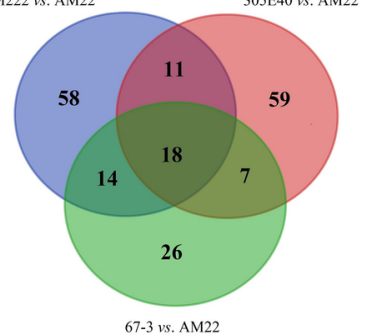

67-3 vs. AM22$$
\text { b. GO:0010035 }
$$

response to inorganic substances
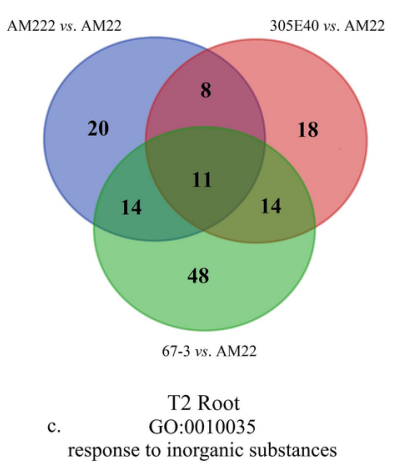

AM222 vs. AM22 305E40 vs. AM22



T0 Shoot
d. GO:0009628

response to abiotic stimulus

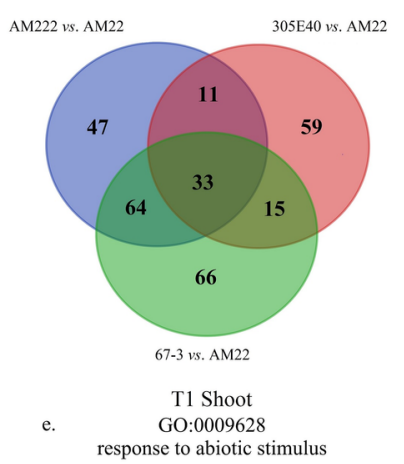

AM222 vs. AM22 305540 vs. AM22

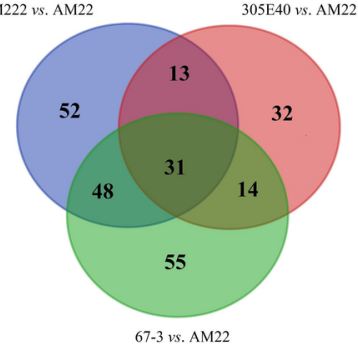

T2 Shoot
f. GO:0042221 response to chemical

AM222 vs. AM22 $305 E 40$ vs. AM22

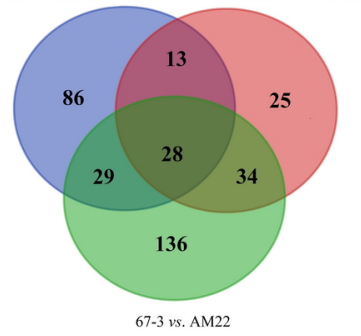


a.

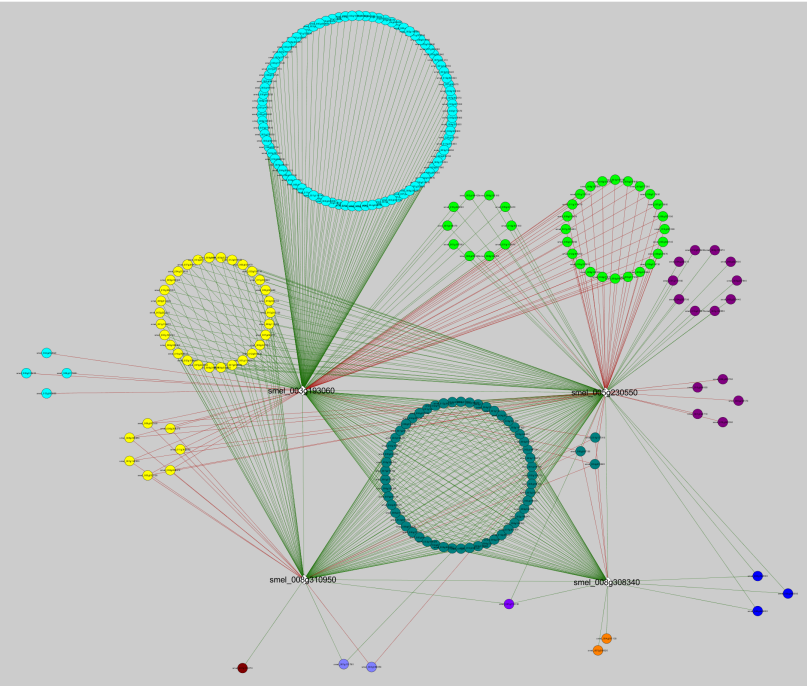

b.

c.

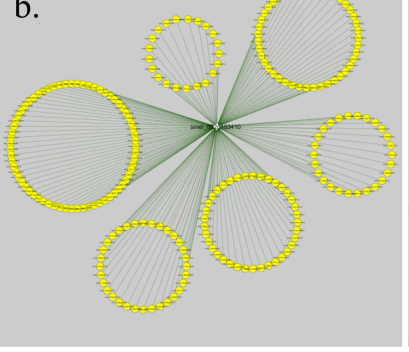

smel_0059238230 -
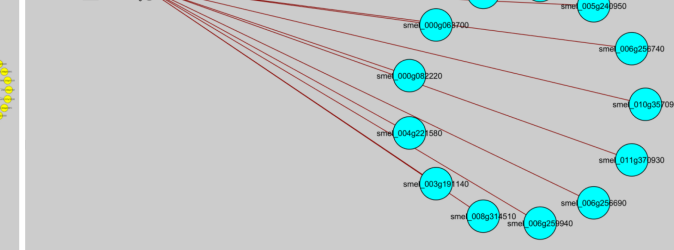

d.





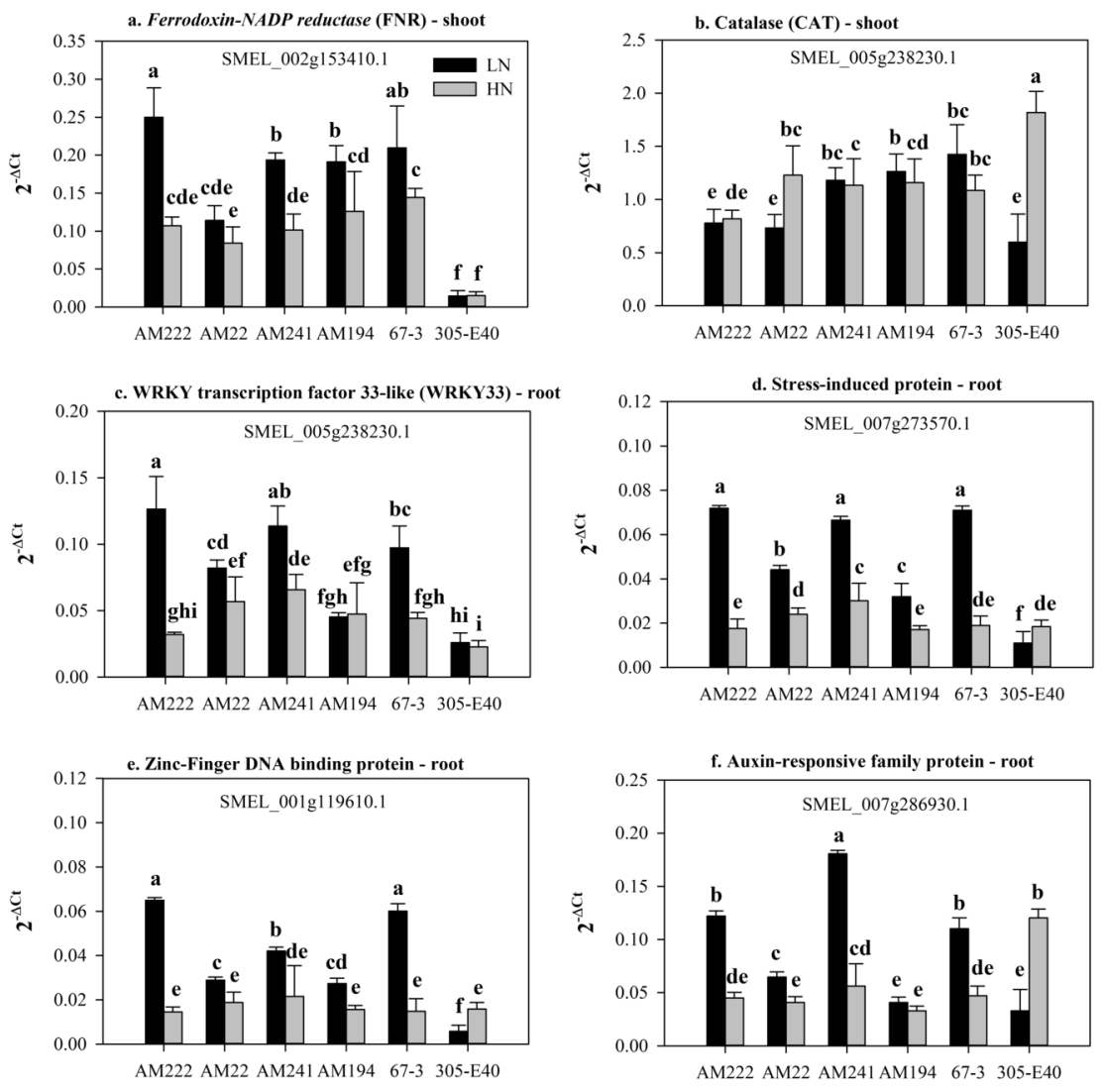

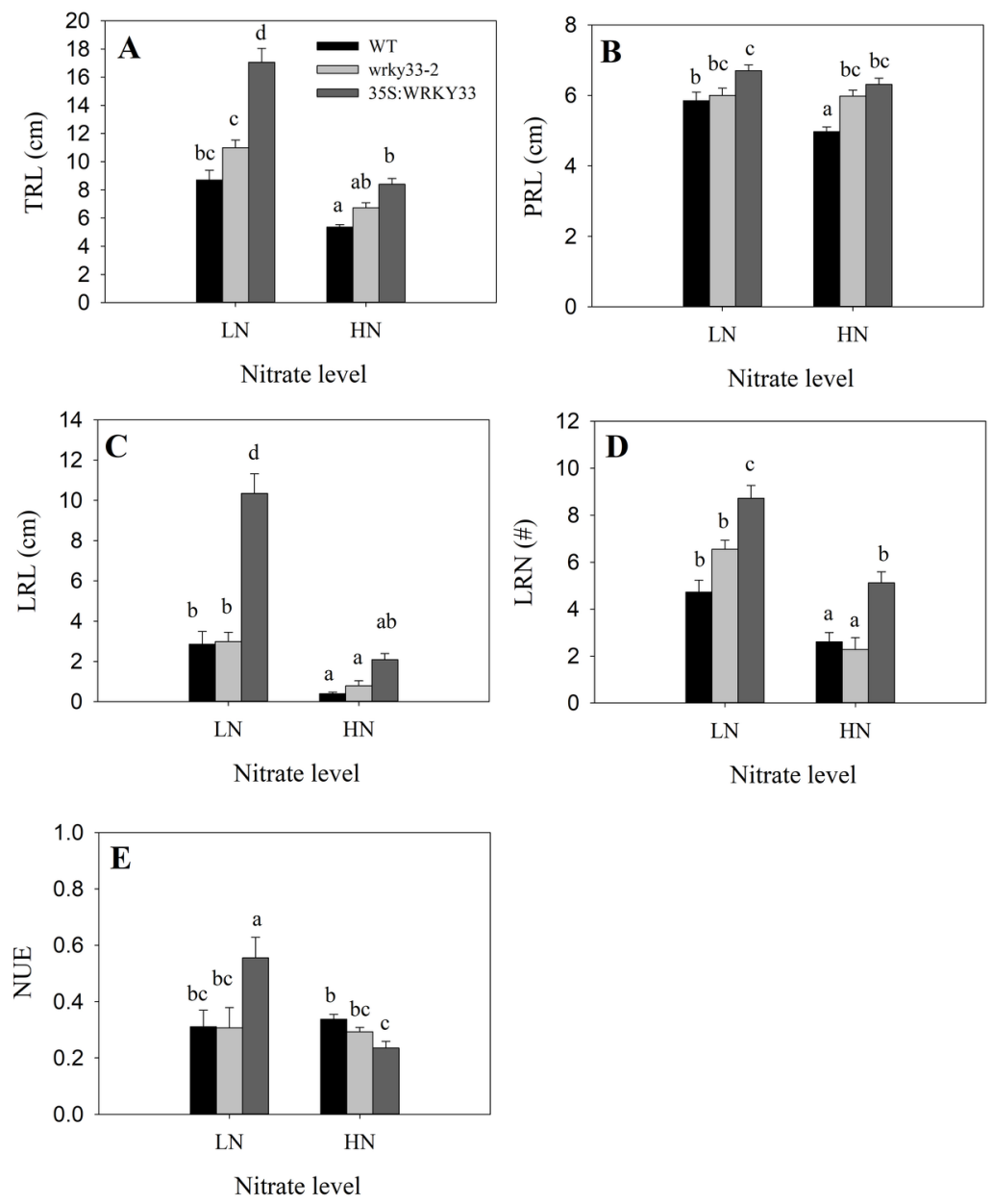